\title{
Advances in the Hydraulic Interpretation of Water Wells Using Flowmeter Logs
}

\author{
Jesús Díaz-Curiel ${ }^{1, *}$, Bárbara Biosca ${ }^{1}$, Lucía Arévalo-Lomas ${ }^{1}$, María Jesús Miguel ${ }^{2}$, Natalia Caparrini ${ }^{3}$ \\ ${ }^{1}$ Department of Energy and Fuels Systems, School of Mines and Energy, Universidad Politécnica de Madrid. Madrid, 28003, \\ ${ }^{2}$ Gobierno de España - Ministerio de Ciencia e Innovación. Madrid, 28046, Spain \\ ${ }^{3}$ Department of Natural Resources and Environmental Engineering, School of Mining Engineering, Universidad de Vigo. \\ Pontevedra, 36310, Spain
} 5 Spain

Correspondence to: Jesús Díaz-Curiel (j.diazcuriel@upm.es)

10 Abstract. This paper reports on the methodology developed for a new hydraulic interpretation of flowmeter logs, allowing a better characterization of continental hydrological basins. In the course of a flowmeter log, different flow stretches are established mostly corresponding to permeable layers (aquifers), among which there are other stretches mainly corresponding to less permeable layers (aquitards). In such hydrological basins of sufficient thickness, these flow stretches may not have the same hydraulic head. This fact brings about the need for a new hydraulic interpretation that provides the actual distribution of

15 horizontal permeability throughout the aquifer at depth. The modified hydraulic interpretation developed in this study focuses on the differences of the effective pressure gradient (considered as the difference between the hydraulic head in the well and the hydraulic head of each stretch) experienced by the different flow stretches along the well, due to the existence of different hydraulic heads. The methodology has been developed starting from a water well located in a multilayered aquifer within the so-named Madrid Basin (the NW part of the continental basin of the Tajo River), located in the centre of the Iberian Peninsula.

20 In this well, a step-drawdown pumping test was conducted, in which the pumping rate versus drawdown and the specific capacity versus drawdown showed discrepancies with Darcian behaviour and an exponent of the Jacob equation of less than 1. Flowmeter logs were then recorded for different discharge rates and pump depths; the resulting water input from deeper permeable layers did not appear to show the expected relation with respect to drawdown. With the proposed methodology the results comply with the expected linearity and the cited discrepancies are solved.

\section{Introduction}

One of the most interesting hydrogeological aspects of well pumping tests is that their results not only allow us to estimate the permeability and transmissivity obtained in the well but can also be used to infer the behaviour of the aquifer when the lithological distribution of the basin in its location is known. In the case of step-drawdown pumping tests, this inference is generally known when the characteristic curves of the test show a conventional evolution, i.e., when the drawdown versus the extraction rate curve shows an increasing slope and the specific capacity decreases with drawdown. This is the case when, 
inside the well, in the near-wellbore zone or in the aquifer, head losses occur, whether linear or polynomial, whose effects are well recognised in step-drawdown pumping test curves (Helweg, 1994; Kawecki, 1995; Mathias and Todman, 2010).

These models provide an accurate representation of the aquifer behaviour for any pumping time. Among other results, Mathias and Todman (2010) found that the best fit was achieved by using a non-linear behaviour coefficient that can be different for each step, obtaining its values by means of an analytical formula derived to relate this coefficient to the Forchheimer parameter. When the drawdown versus the extraction rate curve presents an increasing slope (as in the case of the step-drawdown test from Clark (1977)), there are different hydrogeological explanations. However, when the slope decreases and the specific capacity versus the drawdown increases, i.e., when the hydric behaviour improves with increasing flow rate (as in the last two stages of the step-drawdown test from Van Tonder et al., 2001), the only explanation known to date is that the well is not properly developed. In the following text, when such results occur, they are referred to as anomalous cases.

In step-drawdown pumping tests, there is no unified criterion for the duration that each step should have. Thus, in contrast to the values used for the characteristic curves of these tests in some studies (Shapiro et al., 1998; Karami and Younger, 2002), in this study, it is considered that the steps must be performed for sufficiently long periods to have reached quasi-steady states. These states have been reached when the temporal variation of the drawdown is less than $1 \%$ of the total drawdown for each 45 step. This criterion has been adopted by considering its equivalence with the criterion established by Zha et al. (2017) on the temporal derivative of drawdown for quasi-steady state conditions and by considering the validity of assimilating the drawdown in the well to the average behaviour of the different levels in a multilayer aquifer.

A situation that is not often considered in studies on great continental basins that are hundreds of metres deep is that the diverse permeable layers crossed by water wells can have different hydraulic heads. If this difference exists, then the permeability

50 value determined for each permeable layer is incorrect, leading to an error in the estimation of the flow rate provided by each layer and causing a very important deviation in aquifer modelling. Although this possibility has been cited in several publications (Molz, 1994; Crowder, 2002; Le Borgne, 2006), no methodology has been published to quantify its effects.

This communication presents the possibilities of the flowmeter log to provide a hydrogeological explanation of the described anomalous cases. Flowmeter logging is conventionally used to determine variations in the flow velocity along a well casing,

55 allowing water inputs at different depths that contribute to the total discharge rate to be computed. These quantities are used to estimate changes in hydraulic characteristics with depth, thereby improving the management and rational exploitation of aquifers. In addition to this conventional purpose, a method has been developed in this work that uses flowmeter logs to provide information regarding different hydraulic heads in a multilayer basin. Moreover, determining these different hydraulic heads allows hydraulic reinterpretation that explains the abovementioned anomalous behaviours of the pumping test results.

60 To use flowmeter logs, a thorough pre-processing of results is necessary, without which the water inflow values determined in each filter can have very high errors and in turn allow an accurate determination of the head loss inside the well. Although different types of sensors have been used in well logging tools, spinner flowmeters are the most widely used in assessing the productivity of wells. Díaz-Curiel et al. (2020) proposed a complete reformulation for processing spinner flowmeter logs. 
Another aspect related to the reliability of the flowmeter log results is the variability caused by differences in the near-wellbore or skin zone in the different layers of the well, for whose solution this work proposes the establishment of 'flow stretches'. In this work, the term 'flow stretch' is primarily used for differentiate sets of screens that corresponding to more permeable units (aquifers) among which there are other stretches (aquitards) mainly corresponding to less permeable units. We have chosen to use the term stretch to avoid controversy with other terms such as "units" which have a different hydrogeological meaning. Despite its origin, in this study, the term stretch is used both to designate the flow stretches in the well, as well as the sets of layers to which they correspond. These stretches are obtained from a zonation process of the flowmeter log established by Díaz-Curiel et al. (1997), and it starts by generating a flow curve interpolated between water inputs. This curve is transformed into a smooth curve with constant depth increments. To obtain the depth values at which the limits between stretches are located, first, the inflection points of the smooth curve are calculated, and then the average values between those limits are determined. Finally, the upper and lower limits of each stretch of minimum values (the impermeable stretches) are approximated to each other so that the average variance within each permeable stretch is minimal. These stretches show some parallelism with zonation relative to the average grain sizes shown in Díaz-Curiel et al. (1995), which spatial extension is addressed in the discussion section. The use of the flow stretches allows the differences between screens within each stretch to be ignored, and their influence is not evaluated in this work because the average hydraulic conductivity of each flow stretch compensates for them.

80 Regarding the hydraulic interpretation of flowmeter logs, its main advantage lies in the fact that different permeable layers that the well crosses may have different hydraulic properties. These cannot be drawn from the results of a conventional pumping test without using packers. The differences are quantified by water inputs through screens corresponding to each layer and its thickness. In wells with a high technical control budget, the hydraulic characteristics of the different permeable layers can be achieved by using packers. However, despite the high cost of this technique in deep wells, the results do not have

85 to match those obtained during operations with no packers on the pump. The main reason for this difference is that at higher pumping rates, there is significant vertical flow through the gravel pack surrounding the screen (Boman et al., 1997). For example, for a well drilled to $44.5 \mathrm{~cm}$ and cased with a $39.2 \mathrm{~cm}$ filtering pipe (annulus space $\sim 1400 \mathrm{~cm}^{2}$ ) with a 2-3 mm gravel pack, the flow through it is larger than the water inflow through an isolated screen of $320 \mathrm{~cm}$ (area of $\sim 80000 \mathrm{~cm}^{2}$ ) located in front of sands whose permeability is one hundred lower. By isolating each layer, the static and dynamic water levels may be

90 different from those presented in the well when all permeable layers are connected ('dynamic level' refers to the well water level when it reaches a quasi-steady state for a given pumping rate). The influence of pump depth is not analysed in this study, considering that it only affects the flowmeter logs mainly for measurements in front of the screens close to the pump and that the initial study depths are rather below the pump depth.

To achieve hydraulic interpretation from flowmeter logs, most authors (Molz et al., 1989; Rehfeldt et al., 1992; Ruud and

95 Kabala, 1996; Zlotnik and Zurbuchen, 2003a; Barahona-Palomo, et al. 2011; Riva et al., 2012; Zech et al., 2021) start from the basis that hydraulic conductivity values for each permeable layer (from each screen) are proportional to the hydraulic conductivity of the entire well. In these studies, the hydraulic conductivity is obtained from measurements by a nearby 
piezometer during pumping tests using the Theis equation (1935) between the discharge of a well and the water level drawdown a short distance from the well (Theis, 1963). That proportionality is a function of the ratio between the water input at each screen and the pumping rate and the ratio between the thickness of each screen and the saturated thickness of the aquifer. In mathematical form, the hydraulic conductivity value of the permeable layer $\mathrm{j}$ is given by $K_{\mathrm{j}}=\left(\Delta Q_{\mathrm{j}} / Q_{\mathrm{P}}\right) \cdot\left(\Delta z_{\mathrm{j}} / b\right) \cdot K_{\mathrm{P}},($ Kabala, 1994), where $Q_{\mathrm{j}}$ is the water input at layer $\mathrm{j}, Q_{\mathrm{P}}$ is the extraction rate of the well, $b$ is the aquifer thickness and $K_{\mathrm{P}}$ is the hydraulic conductivity of the entire well. Among the different thicknesses in the literature, saturated thickness (Molz et al., 1989; Li et al., 2008), aquifer thickness (Clemo and Barrash, 2003; Riva et al., 2012) and screened casing thickness (Barahona-

Palomo et al., 2011; Gueting et al., 2017) used to calculate the hydraulic conductivity of an entire well, the saturated thickness is employed in this work.

Unlike the previous procedure, this study follows the less common methodology established by Rehfeldt et al. (1989) starting from the Thiem equation (1906). Although there are contradictory opinions on the validity of this equation, some more recent studies consider that it is still applicable for determining the hydraulic characteristics of the well (Zlotnik and Zurbuchen, 2003b; Schneider and Attinger, 2008; Day-Lewis et al., 2011; Houben, 2015). Rehfeldt et al. (1989) stated that a unique radius of influence $R_{0}$ value (the distance for which the produced drawdown in the aquifer water table is nil) allows the direct determination of the hydraulic characteristics of different permeable layers. Following the proposal in Rehfeldt et al. (1989), variation in the radius of influence can be neglected because it is included in the logarithm; therefore, its variation affects the hydraulic conductivity computation by less than $10 \%$ for all permeable media in a given aquifer. This statement assumes that,

115 for a certain type of aquifer, its radius of influence varies only a few hundred metres around a mean value of approximately one thousand metres (Villanueva and Iglesias 1984).

For these reasons, the goal of this work is to investigate the causes of anomalies in the characteristic curves of pumping tests and to develop a methodology that improves the estimation of the hydraulic parameters in multilayered aquifers. Considering that the hydraulic conductivity $(k)$ of the permeable layers should remain the same at different pumping rates, this advance is based on the fact that the hydraulic head of successive permeable stretches can be different, as already proposed by Bennett and Patten (1960). Although different hydraulic heads are acceptable to determine the hydraulic properties of fractured aquifers (Hess, 1986; Paillet, 2000; Lane, 2002), this is not conventionally taken into account in multilayered aquifers.

This methodology has been applied to a $475 \mathrm{~m}$ deep borehole drilled in a multilayer detrital aquifer located in the centre of the Iberian Peninsula (Madrid Basin). A step-drawdown pumping test was conducted in this well, showing discrepancies with Darcian behaviour and simultaneously with the non-Darcian coefficients of the Jacob equation. The relation between pumping rates and well drawdown in the step-drawdown pumping test as a whole did not show the expected behaviour for the type of aquifer considered. Moreover, the pump characteristic curves that were obtained do not correspond to any aquifer type. This difference results from the fact that the pumping rate increases with drawdown that has a power greater than 1 and that the specific obtained capacity increases with drawdown. A flowmeter log was collected, and the hydraulic interpretation is presented in this study, showing that the activation of the deepest aquifer stretches is the cause of this hydraulic behaviour, as explained throughout this study. 
These results allow the avoidance of the possibly hazardous effects derived from intensive exploitation. As shown in this work, dangerously high arsenic contents occur in the deepest aquifer stretches in the Madrid Basin (López-Vera, 2003). Since the studied well is part of the official network of the Madrid city water supply, it is imperative to limit the spread of this pollutant.

135 As demonstrated by the hydraulic reinterpretation proposed in this paper, this aquifer undergoes strong activation when very high drawdown is applied, producing a sudden increase in its water inputs. This information is key to managing the exploitation network.

\section{Theoretical background}

\subsection{Estimating the hydraulic parameters}

140 To determine the hydraulic conductivity $K$ of the aquifer obtained through the entire well and each permeable layer, the Thiem solution (1906) is used, which is presented by Eq. (1) as a function of the radius of influence $R_{0}$ :

$K=\frac{Q}{2 \cdot \pi \cdot b \cdot d} \ln \frac{R_{0}}{r_{\mathrm{w}}}$

where $Q$ is the extraction rate, $b$ is the aquifer thickness, $d$ is the drawdown in the well, and $r_{\mathrm{w}}$ is the well radius.

The main drawback to this procedure, which is mentioned by Kruseman and Ridder (1970), is the influence of local well

145 factors on the drawdown values. Excluding friction along the pipe (which depends on depth), the different local well factors that modify the obtained hydraulic conductivity of the permeable layers are 1) the reduction in the cross-sectional area of the well due to the submersible pump; 2) the entrance loss caused by flow through the screen slots; 3) the head loss due to the gravel pack; and 4) the head loss caused by the disturbed zone around the well (referred to as the skin effect) (Hufschmied 1986; Rehfeldt et al. 1989). Some of these factors have been considered in detail regarding flowmeter logs (Ruud and Kabala,

150 1997; Ruud and Kabala, 1999). In this work, these factors are not considered because they do not justify an increase or decrease in the hydraulic conductivity with depth; thus, although any of the four factors may have locally different values, their influence on the hydraulic conductivity obtained at each permeable level is constant for any flow.

As established by Rehfeldt et al. (1989), the hydraulic conductivity of each permeable layer is given by Eq. (2):

$K_{j}=\frac{q_{j}}{2 \cdot \pi \cdot \Delta z_{j} \cdot d} \ln \frac{R_{0}}{r_{\mathrm{w}}}$

155 where $q_{j}$ is the water input produced in each screen and $\Delta z_{\mathrm{j}}$ is the thickness of each screen. Equation (2) has been applied in various studies (Xiang 1995; Oberlander and Russell, 2006), but in this work, it is applied to well flow stretches.

\subsection{Step-drawdown pumping test}

In this type of pumping test, the hydraulic behaviour of the well is analysed through the characteristic relationship $d=\mathrm{A} \cdot Q+\mathrm{B} \cdot Q^{2}$ (Jacob 1947) or, in a more general form (Rorabaugh, 1953), as shown in Eq. (3): 
where $Q$ denotes the consecutive values of the extraction rate in each step, $d$ is the corresponding stabilized drawdown (i.e., when its increase is negligible for an increase in the pumping time), A is a constant that depends on transmissivity, and B and $\mathrm{p}$ are fitting constants to the resulting data from the pumping test, where $\mathrm{p}$ is greater than 1 (Todd 1980). The second term represents the apparent divergence from the linearity expected by Darcy's law (Darcy 1856), which is addressed in the Sect. 5.

This is generally attributed to an increase in head loss due to turbulence as the pumping rate increases. It is also coherent when the dynamic level exceeds the depth of the upper aquifer layers, reducing the specific capacity. Although some authors consider that the Jacob equation (Eq. (3)) can be improved, there are still authors who continue to use it (see Mathias and Todman, 2010).

The conventional interpretation of step-drawdown pumping tests begins with the fact that drawdown for different pumping rates is caused by either the general or extensive characteristics of the aquifer. In this way, confined, semiconfined and unconfined aquifers are distinguished, whose curves, pumping rate versus drawdown and specific capacity versus drawdown, are different in each case (Figure 1).
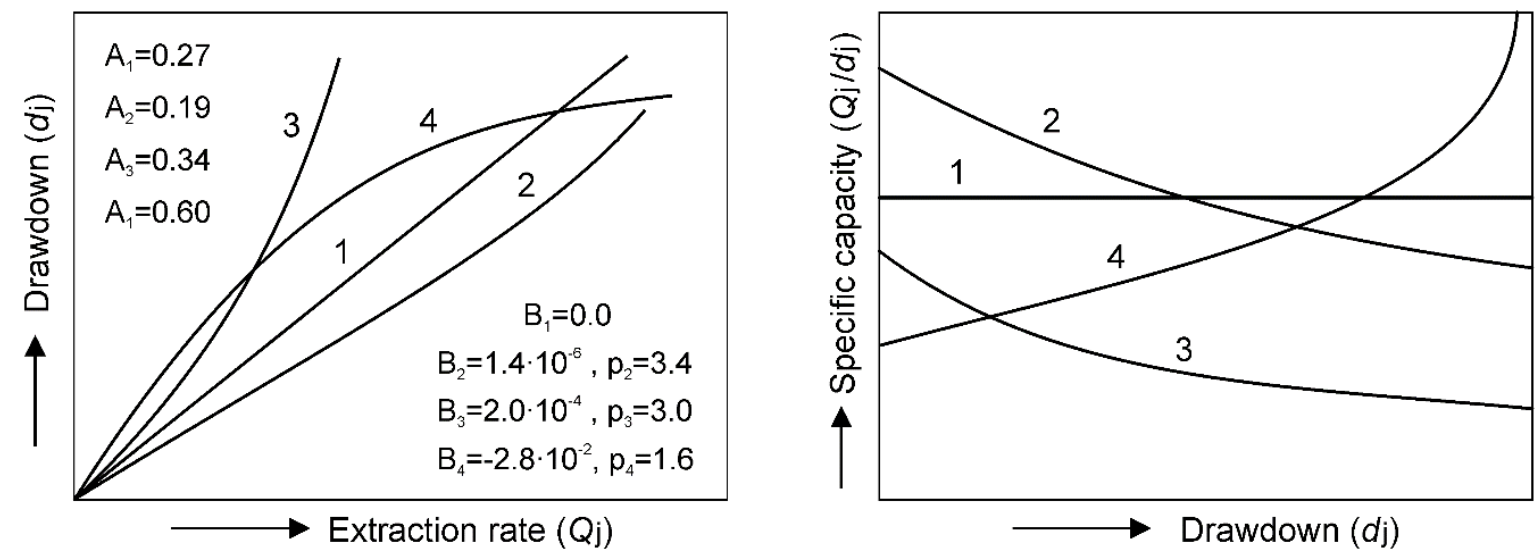

Figure 1. Characteristic curves (adapted from Villanueva and Iglesias 1984), where Aj, Bj and pj are the Jacob equation coefficients.

1) Confined aquifer without head losses in the well. 2) Free aquifer without head losses in the well. 3) Aquifer with nonlinear head losses. 4) Anomalous curve due to, following conventional criteria, poorly collected data or changing characteristics in an aquifer with pumping time.

\subsection{Flowmeter data processing method}

One of the necessary steps is to process the flowmeter logs, this will be done according to the laws of pipe hydraulics using the methodology developed by Díaz-Curiel et al. (2020). To obtain the flow velocity at each depth, $<V(\mathrm{z})>$, a conventional iterative process is used. It begins by taking the measured velocity $V_{\text {meas }}$ at a given depth as the initial flow velocity and the initial Reynolds number $\mathrm{Re}_{\text {ini }}$ according to its definition. Then, a relationship $\tau(\mathrm{Re})$ that provides the flow turbulence exponent $\tau$ as a function of the Reynolds number is applied. Knowing the turbulence exponent and the normalized radius $r_{\mathrm{D}}$ of the sonde 
(the ratio of the sonde distance to the well axis with respect to the well radius), a velocity law must be applied; this law is the ratio between the velocity at the normalized distance $V\left(r_{\mathrm{D}}\right)$ and the maximum velocity in the well axis $V \max$; this allows this maximum value to be obtained. Then, using the relationship for the velocity factor $\mathrm{F}_{\text {vel }}(\tau)$, defined as the ratio between $V$ max and the flow velocity $\langle V\rangle$, the first flow velocity is obtained with the corresponding Reynolds number $\mathrm{Re}_{1}$, which is closer to the actual value. This process is repeated until a given convergence criterion $\mathrm{c}_{\mathrm{CR}}$ is reached, following the flow chart in Fig. 2 (adapted from Díaz-Curiel et al., 2020), to obtain $\operatorname{Re}(\mathrm{z})$.

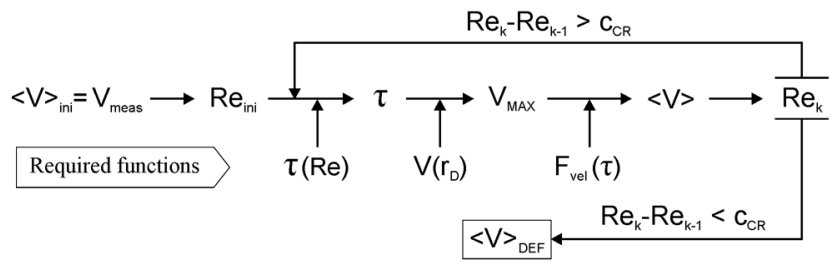

\section{Figure 2. Flowchart of flowmeter log processing.}

The cited relationships are shown in Eqs. (4-6):

$\tau(\operatorname{Re}): \tau=\frac{(\operatorname{Re} / 2490)^{9.994}+1}{0.2 \cdot(\operatorname{Re} / 2490)^{9.9}+1}$

$V\left(r_{D}\right): \frac{V\left(r_{\mathrm{D}}\right)}{V_{\max }}=\left(1-r_{\mathrm{D}}^{\tau+2 / \tau+0.5}\right)^{1 / \tau}$

$195 \quad \mathrm{~F}_{\mathrm{vel}}(\tau): \mathrm{F}_{\mathrm{vel}}=\frac{\langle V\rangle}{V_{\max }}=\frac{\tau+0.5}{\tau+2}$

In these equations, the influence of temperature is not considered because viscosity is practically homogeneous along the well due to water circulation during pumping.

Once the Reynolds number is known, the head loss can be obtained by the Darcy-Weisbach equation (Darcy 1857; Weisbach 1845) using the friction factor for smooth pipes given by Eq. (7):

$f_{\text {smooth }}=\frac{0.3164}{\operatorname{Re}} \frac{\operatorname{Re}^{10.75}+4850^{10}}{\operatorname{Re}^{10}+2850^{10}}$

It is important to point out that according to Eq. (7), as in all pipe hydraulics relations, the friction factor decreases with the Reynolds number except for the transition interval between laminar and turbulent regimes.

\section{Materials and methods}

To estimate the hydraulic parameters from the flowmeter logs, once they have been processed, two specific approaches 205 developed in this work are applied to obtain the actual hydraulic conductivity of the different layers. The first approach is to divide the well into flow stretches with different hydraulic behaviours as a function of the flowmeter results. The second 
approach is based on the fact that the hydraulic head of the deepest flow stretches of the well do not necessarily match the head of the overall well (Fig. 3).

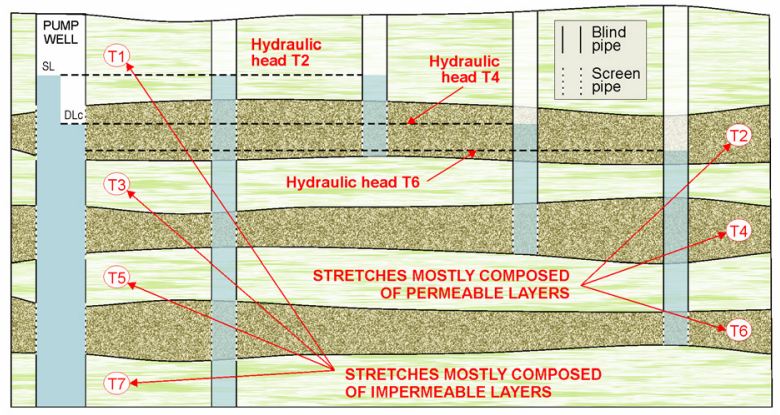

Figure 3. Scheme of the resulting hydraulic head from the existence of permeable stretches with different hydraulic heads.

The hydraulic head of a flow stretch is defined as its effective static level, that is, the height of the water level that would be achieved if the well were connected with the aquifer only through this stretch. This work proposes that a flowmeter log allows us to know the existence of hydraulic heads that are different for each stretch. This distinction implies changes in the effective drawdown of each stretch, which justifies, as shown in the case study, that the water inputs of the deeper aquifer stretches are not proportional to drawdown.

In most pumping tests, the drawdown used in the Thiem (1906) equation is the same for all of the aquifer stretches in a well, while under the hypothesis presented in this work, the hydraulic head of each stretch, and therefore the corresponding drawdown, can be different. Numerically, the drawdown of each flow stretch $\mathrm{T}_{\mathrm{N}}$ is given by the following equation:

$d_{\mathrm{N}}(\mathrm{s})=h_{\mathrm{DL}}(\mathrm{s})-h_{\mathrm{SL}}(\mathrm{N})$

220 where $h_{D L}(s)$ is the dynamic level of the entire well for the 's' pumping step and $h_{\mathrm{SL}}(\mathrm{N})$ is the static level for flow stretch $\mathrm{T}_{\mathrm{N}}$. In short, the proposed method consists of replacing the single drawdown d in Eq. (2) from Rehfeldt by a drawdown for each stretch.

The proposed method for obtaining the hydraulic head of each flow stretch is to 1) correct the drawdown values of the total head loss due to flow along the pipeline and 2) modify the height of the hydraulic head for each flow stretch until the straight line fitted to the data, $q_{\mathrm{N}}(\mathrm{s})$ versus $d_{\mathrm{N}}(\mathrm{s})$, reaches the maximum regression coefficient (where $q_{\mathrm{N}}(\mathrm{s})$ is the water input in flow stretch $\mathrm{N}$ for the pumping steps). With a static level value for each flow stretch, the effective drawdown of each flow stretch can be obtained, and although other local well factors may cause differences between screens within each stretch, their influence is not evaluated in this work because the average hydraulic conductivity of each flow stretch compensates for them. 
https://doi.org/10.5194/hess-2021-380

\section{Case study}

\subsection{Geology of the area and well characteristics}

The study well (named CNC in this work) is located in the Tajo River Basin on the Iberian Peninsula. More specifically, it is located in the western sub-basin, also known as the Madrid Basin, near the city of Madrid (Spain). The Madrid Basin has a triangular shape and is bound by several mountain systems of igneous-metamorphic nature, which are significant contributing source areas. The structure of the basement corresponds to that of a complex graben and has resulted in a sediment thickness of approximately $1000 \mathrm{~m}$, although in some areas, the thickness can exceed $3000 \mathrm{~m}$. The Tertiary (Miocene) sediments that fill the basin correspond to continental deposits of an arid, endorheic nature that are fed by alluvial fans; these alluvial fans develop edge or detrital facies, intermediate or transitional facies, and central or chemical facies, all of which are characteristic of this depositional system (Navarro et al., 1993).

The aquifer is located in a detrital facies single arkosic unit separated into two lithostratigraphic units, which are differentiated by grain size and, therefore, by hydrogeological characteristics; due to the depositional process of the materials, they are differentiated from one area to another as well as vertically. The lower unit, the Tosco Formation, is composed of arkose that is generally very clayey with clayey sand. The upper unit, the Madrid Formation, consists of arkosic coarse-grained sand, gravel and clay. Although the Madrid Formation is sandier and permeable and overlaps the more clayey Tosco Formation, they are not considered different aquifers (López-Vera 1985) but rather a heterogeneous and anisotropic free aquifer system where more permeable layers are separated by clayey strata with a lower permeability (which qualifies as a multilayer aquifer).

Figure 4. Well logs in CNC borehole together with the lithologic section.

A lithological column was compiled from information provided by the detritus

from the borehole and conventional well logs; the normal resistivity and natural gamma ray records are presented in Fig. 4. Note that the logs were not corrected for borehole diameter, conductivity or mud density; therefore, there was a notable difference between the larger diameters in the upper part and the base. Three differentiated parts were established: the first ( 0 to $75 \mathrm{~m}$ ) was composed of sands alternating with thin layers of clay, the second ( 75 to $285 \mathrm{~m}$ ) comprised alternating sandy clay and thin sandy layers, and the third ( 285 to $485 \mathrm{~m}$ ) had a predominance of
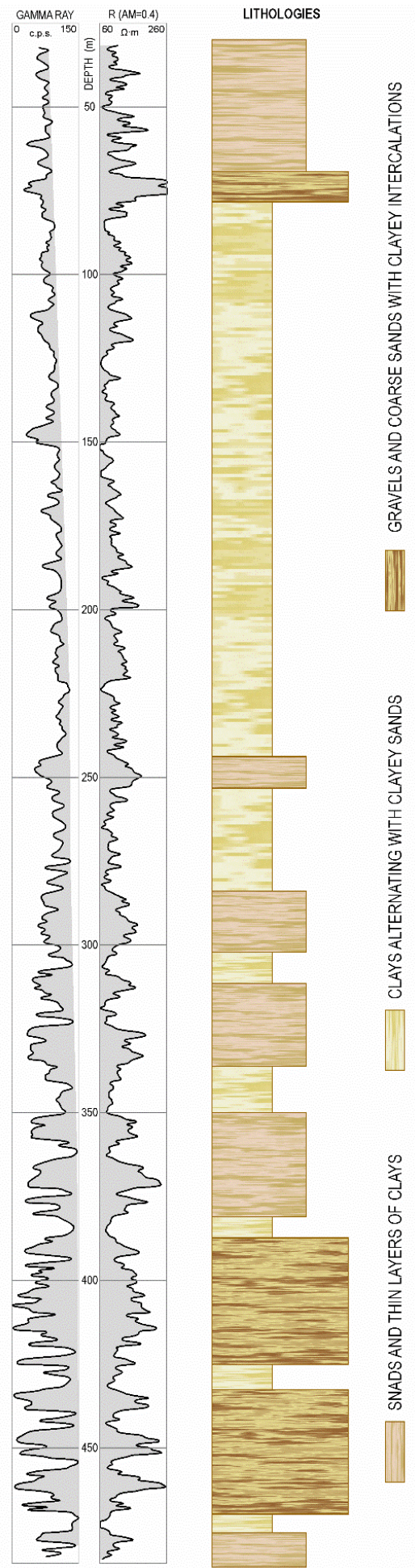
coarse sand and gravel with intercalations of very thick clay layers. As a result of the correlation between lithological stretches in the NW zone of the studied basin (Díaz-Curiel et al., 1995), the permeable stretches can be considered radially homogeneous differentiated aquifers. With the exception of the superficial part, the rest of the permeable stretches can be treated as confined aquifers. This allows the use of the Thiem equation for these stretches and for obtaining hydraulic parameters on a regional scale (as proposed by Rehfeldt) by averaging the stretches as a whole (Sánchez-Vila, 2006).

The borehole was rotary drilled with a diameter of $660 \mathrm{~mm}$ down to a depth of $120 \mathrm{~m}$, and then it was drilled with reverse injection of natural mud with a diameter of $445 \mathrm{~mm}$ to a final depth of $490 \mathrm{~m}$. The construction details of the well consisted of casing to a depth of $480 \mathrm{~m}$, with a $404 \mathrm{~mm}$ inner diameter in the sections of blind pipe and $392 \mathrm{~mm}$ in the wire-wrap screen sections; a gravel packing of 2-3 mm grains was added throughout its length. The well was developed by adding previously diluted polyphosphates, and after 12 hours, a series of intermittent pumping was carried out; once the extracted water contained no suspended fines, a 72-hour gauging of increasing pumping was conducted up to a flow rate of $100 \mathrm{l} / \mathrm{s}$.

\subsection{Pumping test results}

After a process was conducted to eliminate the well storage effect, the static level settled at a depth of $151 \mathrm{~m}$. The pumping test started with a flow of $5 \mathrm{l} / \mathrm{s}$ until the hydraulic head stabilized. Two main extraction pumping rates of 30 and $70 \mathrm{l} / \mathrm{s}$ and a final rate of $75 \mathrm{l} / \mathrm{s}$ were then used, with a total elapsed time of 80.5 hours. All steps were performed for a sufficient time to reach the quasi-steady conditions mentioned in the Sect. 1. The resulting temporary data are shown in Fig. 5, and the drawdown values for each pumping rate are shown in Table 1.

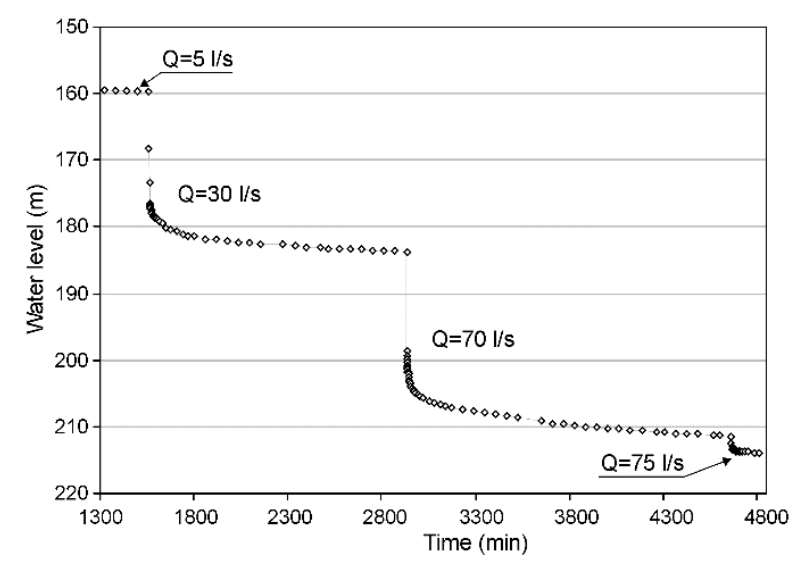

280 Figure 5. Water level versus time during the step-drawdown pumping test in the case study.

Hydraulic conductivity values were obtained using Eq. (1) (Thiem 1906), taking the saturated thickness to be equal to $329 \mathrm{~m}$ (the depth of the well minus the depth of the static level) and considering a radius of influence of $950 \mathrm{~m}$ once the quasi-steady state was reached. This last datum is the central value of those shown in Villanueva and Iglesias (1984) for semiconfined and confined aquifers. The resulting hydraulic conductivity values of the well are shown in Table 1, and they increase with drawdown. 
Table 1. Pumping test results in the case study

\begin{tabular}{ccccc}
\hline $\begin{array}{c}Q \\
(1 / \mathrm{s})\end{array}$ & $\begin{array}{c}\text { D.L. } \\
(\mathrm{m})\end{array}$ & $\begin{array}{c}d \\
(\mathrm{~m})\end{array}$ & $\begin{array}{c}Q / d \\
\left(\mathrm{~m}^{2} / \mathrm{s}\right)\end{array}$ & $\begin{array}{c}K \\
(\text { darcy })\end{array}$ \\
\hline 5.0 & 159.6 & 8.6 & $5.81 \cdot 10^{-4}$ & $2.6 \cdot 10^{-4}$ \\
\hline 30 & 183.7 & 32.7 & $9.17 \cdot 10^{-4}$ & $4.0 \cdot 10^{-4}$ \\
\hline 70 & 211.4 & 60.4 & $11.6 \cdot 10^{-4}$ & $5.1 \cdot 10^{-4}$ \\
\hline 75 & 213.9 & 62.9 & $11.9 \cdot 10^{-4}$ & $5.2 \cdot 10^{-4}$ \\
\hline
\end{tabular}

$Q$ : pumping rate

D.L.: dynamic level

$d$ : drawdown

$K$ : hydraulic conductivity

The hydraulic conductivity values that were obtained do not have to coincide with the general values of the aquifer (since the general values of the well also depend on the construction details) or with those obtained for each of the different permeable stretches that the well crosses (since the result for the well is an average behaviour of those flow stretches). However, it is possible to speak of a mean value (geometric average) of approximately $3.9 \cdot 10^{-4}$ darcy. To hydraulically characterize the well from the pumping test results, Fig. 6 shows the pumping rate versus drawdown $Q(d)$ and the specific capacity versus drawdown

$Q / d(d)$.

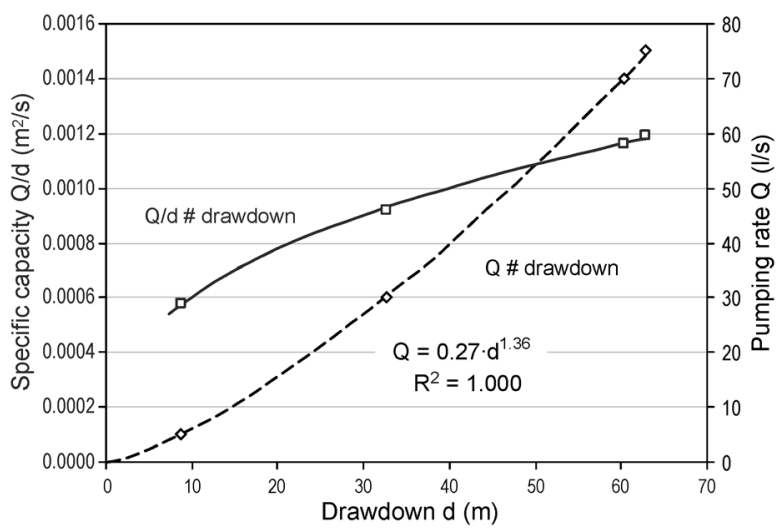

Figure 6. Drawdown versus the pumping rate and the specific capacity versus drawdown in the case study.

Let us remember that in the characteristic equation $d=A \cdot Q+B \cdot Q^{p}$ for the well for step-drawdown pumping tests, the first term corresponds directly to Darcy's law (1856) for the total volume of the water flow crossing through successive cylindrical layers. In the second term, the exponent $p$ can be greater than 1; successive drawdown should show a power relationship with an exponent greater than 1 versus the pumping rate. Moreover, the specific capacity should decrease with successive drawdown; otherwise, the well extraction ratio would increase with drawdown. However, in Fig. 6, the opposite pattern is observed, i.e., $d(Q)$ increases with a power that is less than 1 , and $Q / d$ increases with drawdown. These anomalies do not seem to arise from errors in the water level measurement, as their values versus time appear to be correct (Fig. 5). 


\subsection{Flowmeter results}

The static level was measured at a depth of $157 \mathrm{~m}$ before the beginning of flowmeter logging. Flowmeter logs were obtained for pumping rates of 20 1/s (measured dynamic level at $172 \mathrm{~m}$ ), 30 1/s (dynamic level at $178 \mathrm{~m}$ ), and 70 1/s (dynamic level at $205 \mathrm{~m}$ ). Since the flowmeter logs were collected during pumping operations, measurements could be obtained only below the pump depth. For the pump located at a depth of $191 \mathrm{~m}$, logs were recorded from $200 \mathrm{~m}$ to $470 \mathrm{~m}$ for pumping rates of 20 and $30 \mathrm{l} / \mathrm{s}$, and for the pump located at $253 \mathrm{~m}$, logs were recorded from $260 \mathrm{~m}$ to $470 \mathrm{~m}$ for pumping rates of 30 and $701 / \mathrm{s}$.

Equation 5, that of $V(r) / V_{\max }$, used a normalized distance of 0.64 , which corresponds to the ratio $\left(r_{w}-r_{s}\right) / r_{w}$, where $r_{s}$ is the external radius of the spinner frame (the sonde has a device that maintains its hold on the wall) and $r_{w}$ is the inner radius of the well casing. The different diameters (difference $<1 \%$ ) in the screens were not considered due to the difficulty of executing the iterative process to obtain $\langle V\rangle$. The initial velocity values considered in the iterative process were obtained by applying the calibration curve to the velocities measured by the sonde. The initial Re values varied between 860 and 211000 for all flow rates and pumping rates. For $\tau(R e)$, Eq. (4), the resulting values of the turbulence exponent varied from 1.0 to 6.7 , resulting in values of $\langle V\rangle / V\left(r_{D}\right)$ between 0.85 and 0.94 . The velocity factor values determined using Eq. (6) were in the range of 0.50 to 0.83 , and deviations with respect to the average value reached $35 \%$. In addition to the zone where the studied well is located, there is no geothermalism at all, and the influence of temperature is not considered, as in the common equations on the hydraulic characterization of aquifers.

Figure 7 shows the results obtained for the main parameters and ratios of processing flowmeter logs by applying the methodology of Díaz-Curiel et al. (2020).

The accuracy of the measuring equipment was $0.5 \mathrm{l} / \mathrm{s}$, which greatly reduced the reliability of the results between consecutive screens and produced strong variation in the quantified water inputs from each screen.

\subsection{Head loss results}

The head loss was calculated using the Darcy-Weisbach equation (Darcy, 1857; Weisbach, 1845), and the friction factor was calculated using Eq. (7). The curve of the friction factor values obtained for pumping rates of 20, 30, and $70 \mathrm{l} / \mathrm{s}$ is shown in Fig. 7. Depending on the scale on which the transition interval is analysed, the turbulence of the fluid flow cannot be determined at all points along its path. In this study, we chose to use a fitting expression for smooth pipes given by Eq. (7) because the flowmeter sondes used in well logging reflect the fluid advance on a much larger scale. The friction factor for low pumping rates in the deep screens increased by a maximum of $70 \%$ compared to that obtained using conventional equations. The total head loss below the pump is obtained by integrating the head loss throughout the well based on the flow velocity obtained at each depth (see Fig. 7). Above the pump depth, the calculation is based on a linear increase in the velocity between the pump depth and the dynamic level. The obtained values are shown in Table 2. 

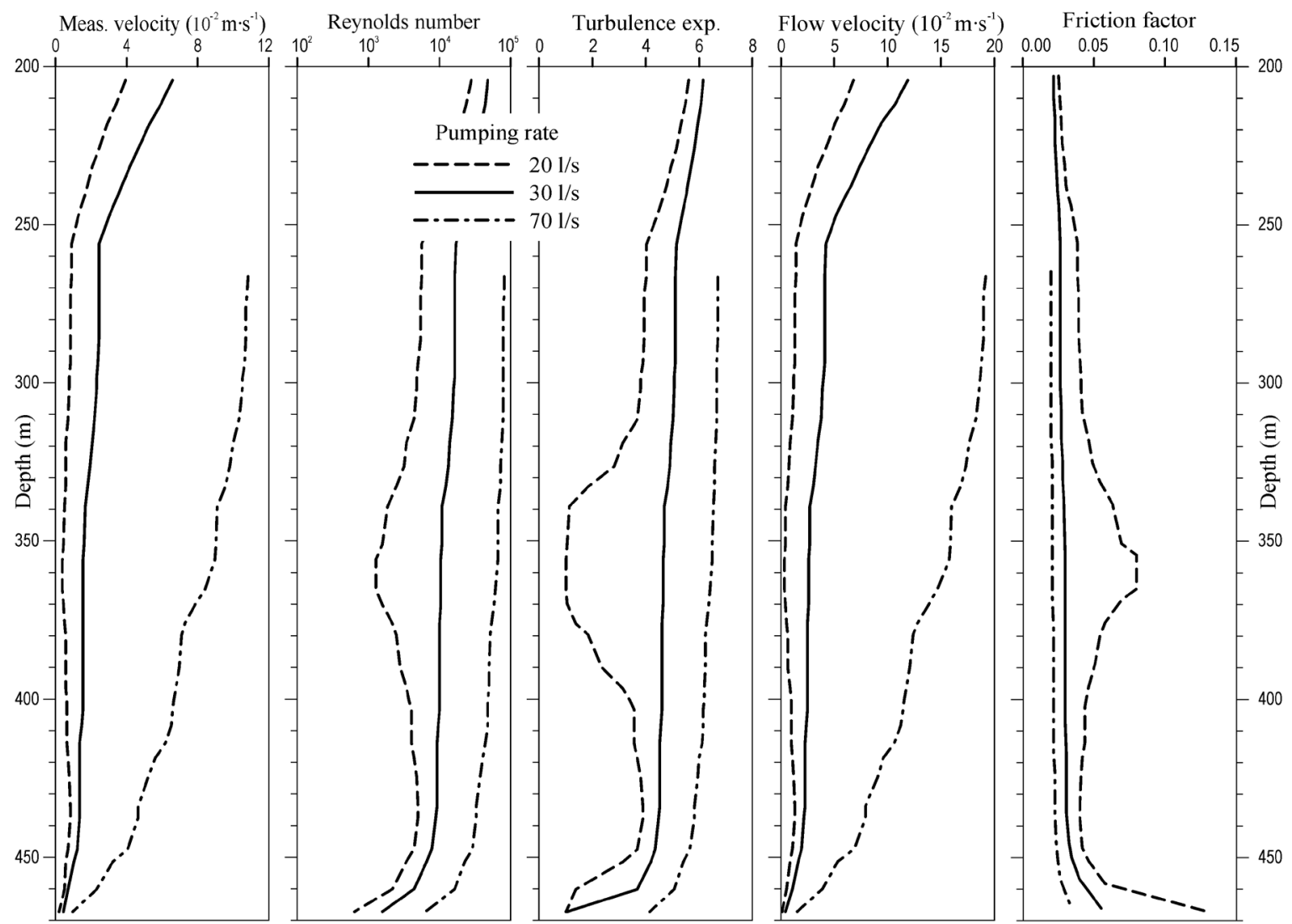

Figure 7. Results obtained for the main parameters in the case study and the calculated friction factors.

Table 2. Head loss values for each pumping rate in the case study

\begin{tabular}{cc}
\hline$Q(1 / \mathrm{s})$ & $\Delta h(\mathrm{~m})$ \\
\hline 20 & 0.06 \\
\hline 30 & 0.92 \\
\hline 70 & 5.42 \\
\hline
\end{tabular}

In this case, the friction factor reaches values six times higher at the bottom of the well than at the initially recorded depth, and

the value of the head loss is low $(0.006 \mathrm{~m})$ because the average velocity in the Darcy-Weisbach equation is raised to a power of two. Therefore, in large-diameter water wells, the influence of the friction factor along the pipeline is negligible. Finally, despite the inclusion of head loss values, the water inputs from some of the stretches still do not maintain the expected proportionality with drawdown, so hydraulic reinterpretation is carried out using the flowmeter results. 


\subsection{Water inputs}

345 Figure 8 shows the results from different pumping rates after processing. On the left-hand side of Fig. 8a, the curves for upward flow rates versus depth are shown, and in Fig. 8b, the water inputs deducted in the different screens are shown, while the negative water inputs (outputs) are not shown in Fig. 8b.

Note that the accuracy provided by the equipment is $0.05 \mathrm{l} / \mathrm{s}$, which greatly reduces the reliability of the results between consecutive screens and produces strong variations in quantifying the water inputs from each screen. For this reason, following the criteria described in the Sect. 3, the flowmeter log is divided into different flow stretches based on the average productivity of each flow stretch.

Table 3 shows the water inputs from the different flow stretches for each measured depth interval. A "top" stretch has been added to the top of the well above the pumping depth, where the different water inputs are unknown. The water input in the upper part (which includes flow stretch $\mathrm{T}_{1}$ for the case of a pumping rate of $70 \mathrm{l} / \mathrm{s}$ ) is obtained by the difference between the pumping rate and the deduced flow rate at that depth.

At a pumping rate of $70 \mathrm{l} / \mathrm{s}$, the water input from flow stretch $\mathrm{T}_{1}$ is not known, and the input of this flow stretch may increase in proportion to the pumping rate, which should imply that the upper part of the well would remain constant (e.g., due to the dynamic level dropping below some of the upper layers).

Both Fig. 8 and Table 3 show that the water input from flow stretch $\mathrm{T}_{2}$ is very low, even for high pumping rates, and it is close to the flowmeter accuracy; hence, that flow stretch is omitted from the analysis.

Table 3 shows that for pumping rates of 20 and 30 1/s, the water inputs from the upper part of the well and from flow stretches $\mathrm{T}_{1}, \mathrm{~T}_{3}$, and $\mathrm{T}_{6}$ increase in a way that is practically proportional to the flow (with a ratio $\approx 1.5$ ) and fits a confined aquifer. Flow stretches $\mathrm{T}_{4}$ and $\mathrm{T}_{5}$ have negligible water inputs, reaching negative inputs for a pumping rate of $20 \mathrm{l} / \mathrm{s}$. However, for the $70 \mathrm{l} / \mathrm{s}$ pumping rate, there is an abrupt change in the hydraulic behaviour of the well. On the one hand, the whole water input from the upper part of the well and from flow stretch $\mathrm{T}_{1}$ do not increase proportionally to the pumping rate (ratio $=2.33$ ). On the other hand, flow stretch $\mathrm{T}_{6}$ shows a sharp increase in the water inputs, and flow stretches $\mathrm{T}_{4}$ and $\mathrm{T}_{5}$ present an apparent activation. Given the possibility that an increase in the head loss could justify such behaviour, values for each pumping rate were calculated and added. 

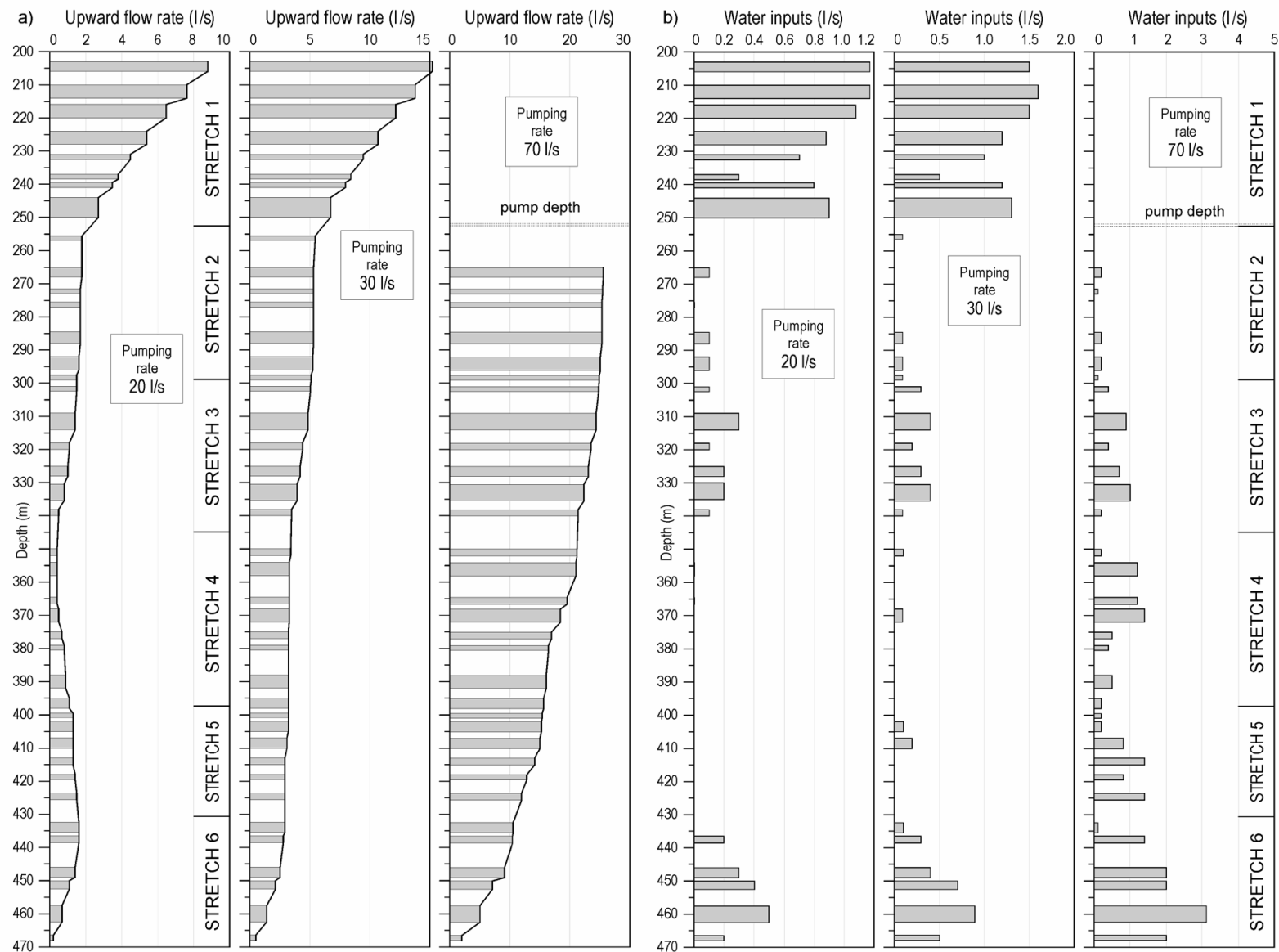

Figure 8. Flowmeter results in the case study: a) upward flow rate versus depth; b) water inputs from each screen.

The high correlation of the water inflows in stretches 2 and 3 for the pump located at the depths of $191 \mathrm{~m}$ and at $253 \mathrm{~m}$, confirms the consideration that the depth of the pump does not affect the values obtained with the flowmeter logs.

Table 3. Water inputs of flow stretches for different pumping rates and fractions over the total flow rate $\mathrm{Q}_{\mathrm{T}}$ in the case study

\begin{tabular}{|c|c|c|c|c|c|c|c|}
\hline \multirow[b]{3}{*}{ Stretch } & \multirow[b]{3}{*}{$\begin{array}{l}\text { Depth } \\
\text { (m) }\end{array}$} & \multicolumn{6}{|c|}{ Pumping rate $Q_{\mathrm{T}}(\mathrm{l} / \mathrm{s})$} \\
\hline & & \multicolumn{2}{|c|}{20} & \multicolumn{2}{|c|}{30} & \multicolumn{2}{|c|}{70} \\
\hline & & $\begin{array}{c}\text { Input } \\
(1 / s)\end{array}$ & $\begin{array}{c}\% \text { of } \\
Q_{T}\end{array}$ & $\begin{array}{c}\text { Input } \\
(1 / s)\end{array}$ & $\begin{array}{c}\% \text { of } \\
Q_{\mathrm{T}}\end{array}$ & $\begin{array}{c}\text { Input } \\
(1 / s)\end{array}$ & $\begin{array}{c}\% \text { of } \\
Q_{\mathrm{T}}\end{array}$ \\
\hline Top & $0-200$ & 10.2 & 0.53 & 14.8 & 0.49 & \multirow{2}{*}{44.5} & \multirow{2}{*}{0.64} \\
\hline $\mathrm{T}_{1}$ & $203-250$ & 7.0 & 0.34 & 9.8 & 0.33 & & \\
\hline $\mathrm{T}_{2}$ & $250-300$ & 0.4 & 0.02 & 0.4 & 0.01 & 0.8 & 0.01 \\
\hline $\mathrm{T} 3$ & $300-360$ & 1.1 & 0.06 & 1.7 & 0.06 & 3.8 & 0.05 \\
\hline $\mathrm{T} 4$ & $360-400$ & -0.9 & -0.05 & 0.1 & 0.00 & 5.8 & 0.08 \\
\hline T5 & $400-430$ & -0.3 & -0.02 & 0.4 & 0.01 & 4.6 & 0.07 \\
\hline T6 & $430-470$ & 1.6 & 0.08 & 2.9 & 0.10 & 10.5 & 0.15 \\
\hline
\end{tabular}


375 Regarding the existence of different hydraulic heads, note that the negative water input in flow stretches $\mathrm{T} 4$ and $\mathrm{r} 5$ for the pumping rate of $20 \mathrm{l} / \mathrm{s}$ corroborates the validity of the hypothesis in this work. These negative inputs reflect the fact that when the drawdown is located above the hydraulic head of these flow stretches, the water flow does not occur inwards towards the well but rather outwards, reducing the upward vertical flow. In any case, the fact that the deeper flow stretches have a hydraulic head below the static level of the well explains that the pumping rate versus drawdown curve adjusts to a power function with an exponent greater than 1, and the specific capacity versus drawdown curve is ascending. There are several studies in the literature that mention negative water inputs as those obtained in this case, but they do not present the hydraulic interpretation thereof, most of them correspond to flow-logs measured in ambient conditions (Paillet et al., 2000; Butler et al., 2009; DayLewis et al., 2011).

\subsection{Hydraulic reinterpretation}

Analysing the specific capacities of different flow stretches and selecting the static level of $157 \mathrm{~m}$ (as determined before the flowmeter logging was conducted), flow stretches $\mathrm{T}_{1}$ and $\mathrm{T}_{3}$ show the expected proportionality for a confined aquifer. However, this is not the case for flow stretches $\mathrm{T}_{4}, \mathrm{~T}_{5}$ and $\mathrm{T}_{6}$, whose $q_{\mathrm{N}}(\mathrm{s})$ versus $d_{\mathrm{N}}(\mathrm{s})$ data fit a power function with exponents of 4.5, 2.7 and 1.5, respectively. Not only does this not reflect Darcian behaviour, but it also indicates an exponent $p$ in the Jacob equation of less than 1, as is the case with the well as a whole (see Fig. 6).

390 However, when flow stretches $\mathrm{T}_{4}, \mathrm{~T}_{5}$ and $\mathrm{T}_{6}$ have different hydraulic heads, the results vary. Through an iterative process, the value of the static level (hydraulic head) of each flow stretch for which the total water input of the flow stretch versus the drawdown acquires greater alignment can be determined. This means that when the data are approximated to a straight line, the regression coefficient is maximum. In other words, the resulting exponent in the Jacob equation when the data are approximated to a power function is $\mathrm{p}=1$. Thus, for flow stretch $\mathrm{T}_{6}$, the static level for which inputs versus drawdown acquire greater alignment occurs at a depth of $165 \mathrm{~m}$. Similarly, the resulting static level for flow stretch $\mathrm{T}_{5}$ is located at a depth of 175 $\mathrm{m}$. For a pumping rate of $70 \mathrm{l} / \mathrm{s}$, flow stretch $\mathrm{T}_{4}$ undergoes an "activation" effect that is even higher than flow stretch $\mathrm{T}_{5}$ when the static level is at a depth of $177.5 \mathrm{~m}$.

Figure 9 shows the regression lines of water inputs versus drawdown for each stretch, with the corresponding relationships and $\mathrm{R}^{2}$ coefficients. 


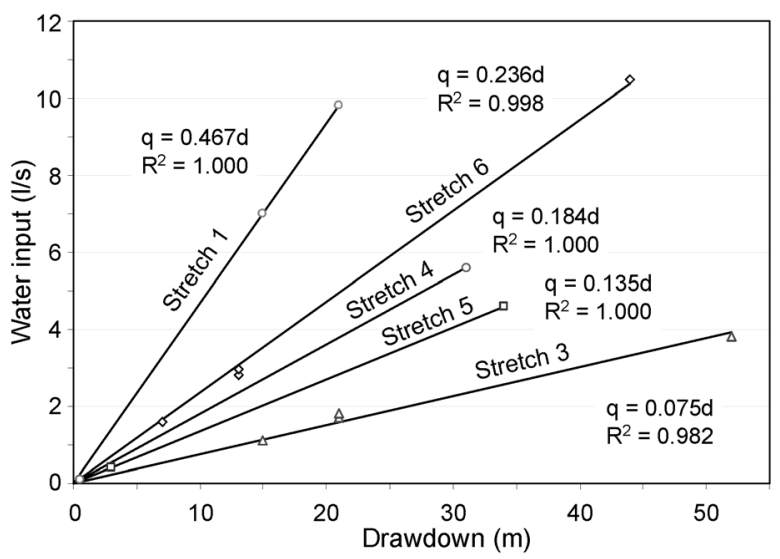

Figure 9. Water inputs versus drawdown for different flow stretches in the case study.

With these differentiated static levels, the hydraulic conductivities of each flow stretch were obtained using Eq. (2) (Rehfeldt et al. 1989) and are presented in Table 4.

Table 4. Specific capacities and permeabilities of flow stretches for the static level determined in the case study

\begin{tabular}{ccrr}
\hline Stretch & $\begin{array}{l}\text { S.L. } \\
(\mathrm{m})\end{array}$ & $\begin{array}{c}Q / d \\
\left(\mathrm{~m}^{2} / \mathrm{s}\right)\end{array}$ & $\begin{array}{c}k \\
(\text { darcy })\end{array}$ \\
\hline Top & 157.0 & - & - \\
\hline $\mathrm{T}_{1}$ & 157.0 & $4.7 \cdot 10^{-4}$ & $1.3 \cdot 10^{-3}$ \\
\hline $\mathrm{T}_{2}$ & 157.0 & - & - \\
\hline $\mathrm{T}_{3}$ & 157.0 & $7.5 \cdot 10^{-5}$ & $2.0 \cdot 10^{-4}$ \\
\hline $\mathrm{T}_{4}$ & 177.5 & $1.8 \cdot 10^{-4}$ & $5.3 \cdot 10^{-4}$ \\
\hline $\mathrm{T}_{5}$ & 175.0 & $1.4 \cdot 10^{-4}$ & $5.4 \cdot 10^{-4}$ \\
\hline $\mathrm{T}_{6}$ & 165.0 & $2.4 \cdot 10^{-4}$ & $1.0 \cdot 10^{-3}$ \\
\hline
\end{tabular}

405

The hydraulic conductivities of the layers in the studied part of the well (200 to $470 \mathrm{~m}$ ) have values between $2 \cdot 10^{-4}$ and $1.3 \cdot 10^{-3}$ darcy, providing a geometric mean value of $5 \cdot 10^{-4}$ darcy, which is close to the average hydraulic conductivity obtained with the pumping tests. The largest contrast occurs with the difference between the hydraulic conductivity values of the different flow stretches, which is close to an order of magnitude.

410 As mentioned at the beginning of Sect. 4, the precision of flowmeter logs does not allow us to obtain reliable hydraulic conductivity values of each permeable layer to make a more detailed characterization of each stretch. However, that analysis could be undertaken by considering the average water input and average thickness. 


\section{Discussion}

Regarding the linearity predicted by Darcy's law, in this work, the variation corresponding to nonlinear flow is a different process than the change in the flow from a laminar to a turbulent regime. Takhanov (2011) determined that the onset of nonlinear flow occurs prior to the change to turbulent flow; in fact, some authors have considered that turbulent flow does not occur in porous fine-grained media in their natural state (Green and Duwez, 1951; Bakhmeteff and Feodoroff, 1937). In this sense, Houben (2015) established a linear laminar regime in the aquifer that becomes nonlinear in the gravel pack and only becomes turbulent on the screen and inside the pipe. In this work, the regime change is less gradual than that predicted by the Forchheimer equation (1901) and does not increase with the same power after the transition. It should be taken into account that both the values of the friction factor and the particle Reynolds number established for the Forchheimer flow decrease as Re increases. To analyse the flow linearity in water wells, the hydraulic characteristics of the flow in the aquifer levels must be quantifiable by the velocity near the well. Moreover, a value of $0.01 \mathrm{~m} / \mathrm{s}$ can be considered the maximum velocity in groundwater near wells. For example, if a water well with a very high extraction rate of $100 \mathrm{l} / \mathrm{s}$, radius of $0.2 \mathrm{~m}$, total length of $400 \mathrm{~m}$ and screened length of $80 \mathrm{~m}(20 \%)$ is considered, then the average water input velocity would be $0.005 \mathrm{~m} / \mathrm{s}$. Considering the results in Lopik et al. (2017), nonlinear behaviour starts at velocities greater than $0.01 \mathrm{~m} / \mathrm{s}$, so the maximum water input still exhibits Darcian behaviour.

Among the possible explanations for the difference in hydraulic head values for the deeper flow stretches are hydrogeological reasons, such as the presence of flow stretches with different vertical transmissivities. However, the approximated values for the hydraulic conductivity in the less permeable stretches ( $\mathrm{T}_{2}$ and $\mathrm{T}_{4}$ ) contradict this hypothesis, since flow stretch $\mathrm{T}_{2}$ is less permeable than flow stretch $\mathrm{T}_{4}$, but flow stretch $\mathrm{T}_{3}$ is not affected by a similar effect. Another possible explanation is that the change in the effective drawdown is due to the existence of nearby extraction wells, which overexploited the aquifers corresponding to flow stretches $\mathrm{T}_{4}$ and $\mathrm{T}_{5}$, thereby producing a drop in the static level of these flow stretches.

Concerning the reliability of the final permeability values, one aspect that must be considered in estimating hydraulic parameters from flowmeter results is that the analysis was conventionally performed through the screens assembled in the casing. However, the distribution of these screens only approximately matches the permeable layers that the well crosses. Hence, differences between the thicknesses of the permeable layers and the assembled screens may exist, as well as permeable layers that are not faced with a screen, whose effects are minimized by gravel packing. This effect adds to that produced by the local factors of the aforementioned well, which is an additional reason for differences in the water inputs of the different screens within each stretch.

Therefore, although the results of the pumping tests and the flowmeter results yield a similar hydraulic conductivity value for the entire well, after considering the possible hydraulic head difference that justifies and relates the anomalies reported over the pumping test data, this value moves away from the actual hydraulic conductivity of the aquifer.

Under the consideration that vertically there is a high hydraulic connection (similar to horizontal one), it is common practice in hydrogeology to model large aquifers as an equivalent porous medium. In addition to obtaining water balance results, such 
models have a wide application in many basins (De Filippis et al., 2016). However, this study focuses on a case where the vertical hydraulic connection is much lower than the horizontal one, as can be deduced from the existence of different hydraulic heads found. In this study, it is considered that the low hydraulic connection due to the existence of one or several wells in a basin of the size studied does not significantly affect the lateral variations of the hydraulic head along the basin. In contrast with several works taking into account the hydraulic head field (Yeh et al., 1996; Axness and Carrera, 1999), in this study it is considered a single hydraulic head for distances smaller than the radius of influence. When wells are continuously screened, on a small scale it can be taken into account that the hydraulic head does not show as abrupt a change as is considered in great continental hydrological basins. In these basins this effect, which causes the conventional hydraulic head field over distance, is included in the hydraulic parameter relationships from the hydraulic head gradient. It is also considered that in the interior of a large diameter well, such as water wells in large continental basins, there is no change with depth of the effective hydraulic head. In oil wells, this possibility is considered because of the strong variations in vertical flow velocity and the use of smaller diameters, leading to higher head losses.

Regarding Jacob's well equation (Eq. (3)), some authors say that the coefficient that multiplies $Q^{2}$ is the turbulent flow coefficient, but others say that when the characteristic curve is not linear, it is because turbulent flow occurs. However, it is not clear what this "turbulent flow" refers to. It does not seem to refer to the change in flow in the pipeline but to the water in the aquifers acquiring turbulent flow. Regarding the friction factor, water flow in granular aquifers is not turbulent, although the obtained Re value would correspond to turbulent flow if the thickness of the aquifer is used to calculate the Reynolds number instead of using a mean pore diameter through which the water circulates.

This contrasts with the complex flow regime in oil wells where gas and liquids of different characteristics are combined, the 465 behaviour of which has been analysed in many publications (Nind, 1965; Hasan and Kabir, 1988; Bri and Arirachakaran, 1992; Kabir and Hasan, 2004; Wu et al., 2017). This may lead one to believe that such behaviour is also common for water. However, if we consider, for example, a pressure gradient reaching $5 \mathrm{~atm}$ and an average pore diameter reaching $2 \mathrm{~mm}$, the Re number obtained for water flow is $<100$, which does not correspond to turbulent flow.

Related to the spatial extension of the different hydraulic heads obtained, there are two facts that should be considered. On the one hand, hydrogeologists who have studied the Madrid Basin are already aware of the increase in arsenic that occurred at other points in the NW part of the basin for high drawdowns (López-Vera 1985). This would confirm that the hydraulic head of the arsenic-contaminated stretches is lower. On the other hand, although, has already mentioned, this part of the basin is classified as a heterogeneous and anisotropic free aquifer system (Samper, 1999; Yélamos and Villarroya, 2007), other studies on borehole correlation in this area show that the stretches established from logs reach distances of more than $10 \mathrm{~km}$ (Caparrini, 475 2006).

Finally, regarding the application of this methodology to other aquifers of the same type, there is no hydrogeological hypothesis that implies that in other great continental basins in which large impermeable-type stretches are found, all the permeable stretches should have the same hydraulic head. 


\section{Conclusions}

480 The improvements developed in this work are represented by the following advances in the hydraulic interpretation of flowmeter logs:

a) The method developed from the flowmeter allows to reinterpret the hydraulic behaviour of any well in which the characteristic curve $d(Q)$ increases with a power less than 1 and the characteristic curve $\mathrm{Q} / \mathrm{d}$ increases with drawdown, which until now was considered anomalous due to poorly measured data or due to changing aquifer characteristics with pumping time.

b) The processing of flowmeter logs provides an increase in the quantified values of water inputs in the deepest permeable media for low pumping rates. This increase modifies the obtained values for hydraulic conductivities in the studied well data that approach Darcian behaviour but do not reach it.

c) The division of the wells into flow stretches with different hydraulic heads provides hydraulic reinterpretation that explains

490 the possible anomalies produced in the step-drawdown pumping tests. As occurs in the well in this study, both the characteristic curve of the pumping test and the specific capacity versus the drawdown curve show unexpected slopes, the anomalous nature of which is not justified by non-Darcian behaviour.

d) In particular, the resulting values of the different hydraulic heads make it advisable, in any well located in the Madrid Basin, not to use pumping rates for which the dynamic level goes beyond the depth corresponding to the drawdown of $165 \mathrm{~m}$ in the

495 studied well. Once it is determined if flow stretches $\mathrm{T}_{4}$ and $\mathrm{T}_{5}$ have a greater arsenic content than flow stretch $\mathrm{T}_{6}$, the mentioned depth can be changed to that corresponding to a drawdown of $175 \mathrm{~m}$ in the studied well.

The verification of the existence of different hydraulic heads for the different stretches with depth entails a substantial change in the hydrogeological knowledge of a basin such as the one studied. It can also be concluded that the corresponding determination of the real hydraulic properties of the different stretches is essential for modelling the hydraulic behaviour of

500 the basin. Likewise, although it does not have a spatial extension corresponding to the entire basin (as there are characteristics that do not necessarily have to be maintained, depending on the position with respect to the different source areas and the distance to them), the extension of up to $10 \mathrm{~km}$ is sufficiently interesting to characterise parts of the basin.

As a future line of action, this study proposes the execution of step-drawdown pumping test and flowmeter logs with various flow rates in wells progressively distant from the studied one to verify that the stretches with different hydraulic heads maintain 505 and to determine the spatial extension of this behaviour. 
Authors contributions. JDC conceptualized the paper. JDC develop the methodology. JDC, MJM and contributed to the writing of the paper, with BBV and LAL reviewing and editing the paper. JDC and NC curated the data and led the investigation. BBV and LAL does the formal analysis and prepared visualization data. JDC supervised the project.

Data Availability Statement. The data used in this manuscript are available for download in the following link https://data.mendeley.com/datasets/gx8dwgvygn/1.

Competing interests. The authors declare that they have no conflict of interest.

Acknowledgments. Authors would like to thank Canal de Isabel II (Madrid, Spain) the permission for using the flowmeter logs and the provided information on the pumping test. Also to Springer's language service the editing of the manuscript (for correctness of English language, grammar, punctuation, spelling and general style).

520 Financial Support. Part of this work was supported by the Regional Government of Madrid, (CARESOIL-CM project grant number P2018/EMT-4317).

\section{References}

Axness, C.L., Carrera, J.: The 2D steady hydraulic head field surrounding a pumping well in a finite heterogeneous confined aquifer, Math Geol, 31 (7), 873-906, doi.org/10.1023/A:1007528918105, 1999.

Bakhmeteff, B. A. and Feodoroff, N. V.: Flow through granular media, J. Appl. Mech., 4, A97-A104. https://doi.org/10.1115/1.4008783, 1937.

Barahona-Palomo, M., Riva, M., Sanchez-Vila, X., Vazquez-Sune, E. and Guadagnini, A.: Quantitative comparison of impeller-flowmeter and particle-size-distribution techniques for the characterization of hydraulic conductivity variability, Hydrogeol J, 19, 603-612. https://doi.org/10.1007/s10040-011-0706-5, 2011.

530 Bennett, G. D. and Patten, E. P. Jr.: Borehole geophysical methods for analyzing specific capacity of multiaquifer wells, U.S. Geological Survey Water-Supply Paper 1536-A, p. 1-25, 1960.

Boman, G. K., Molz, F. J. and Boone, K. D.: Borehole flowmeter application in fluvial sediments: Methodology, results and assessment, Groundwater, 35(3), 443-450. https://doi.org/10.1111/j.1745-6584.1997.tb00104.x, 1997.

Brill, J.P., Arirachakaran, S.J.: State of the art in multiphase flow. J. Pet. Technol., 44(05), 538-541, doi.org/10.2118/23835535 PA, 1992.

Butler, A. P., Mathias, S. A., Gallagher, A. J., Peach, D. W., and Williams, A. T.: Analysis of flow processes in fractured chalk under pumped and ambient conditions (UK), Hydrogeol J, 17(8), 1849-1858. http://dx.doi.org/10.1007/s10040-009-0477-4, 2009. 
Caparrini, N.: Interpretación y correlación de registros geofísicos en sondeos de captación de aguas subterráneas para la caracterización hidrogeológica y la gestión de la explotación: aplicación en el arco noroeste de la cuenca de Madrid (Interpretation and correlation of geophysical logs in groundwater collection boreholes for hydrogeological characterisation and exploitation management: application in the northwest arc of the Madrid Basin), Phd Thesis, Universidad Politécnica de Madrid, Madrid, 2006.

Clark, L.: The analysis and planning of step drawdown tests, Q. J. Eng. Geol., 10, 125-143, doi:10.1144/GSL.QJEG.1977.010.02.03, 1977, 1977.

Clemo, T., Barrash, W.: Inversion of borehole flowmeter measurements considering well screen clogging and skin, Proceedings of MODFLOW and more: 3: Understanding through Modeling, 16-19, 2003.

Darcy, H.: Determination des lois d'ecoulement de l'eau a travers le sable: Les fontaines publique de la ville de Dijon (Determination of the laws of water flow through the sand: The public fountains of the city of Dijon). Victor Dalmont, Paris.

550 Appendix, note D, 590-594. 1856.

Darcy, H.: Recherches expérimentales relatives au mouvement de l'eau dans les tuyaux (Experimental research related to the movement of water in pipes) (Vol. 1). Mallet-Bachelier. 1857.

Day-Lewis, F. D., Johnson, C. D., Paillet, F. L., and Halford, K. J.: A computer program for flow-log analysis of single holes (FLASH), Ground Water, doi: 10.1111/j.1745-6584.2011.00798, 2011.

555 De Filippis, G., Giudici, M., Margiotta, S., and Negri, S.: Conceptualization and characterization of a coastal multi-layered aquifer system in the Taranto Gulf (southern Italy), Environ Earth Sci 75, 686, DOI 10.1007/s12665-016-5507-7, 2016.

Díaz-Curiel, J., Miguel, M. J., Caparrini, N., Biosca, B. and Arévalo-Lomas, L.: Improving basic relationships of pipe hydraulics, Flow Meas Instrum, 72, 101698. https://doi.org/10.1016/j.flowmeasinst.2020.101698, 2020.

Díaz-Curiel, J., Miguel, M. J., Caparrini, N. and Domínguez, S.: Determinación automática de las capas paramétricas y de los

560 tramos de diagrafías geofísicas en sondeos (Automatic determination of parametric layers and stretches of well logs), Tierra y Tecnología, Colegio Oficial de Geólogos de España, 18, 78-87, 1997.

Díaz-Curiel, J., Martin, D and Maldonado, A.: Correlación de sondeos mediante diagrafías. Aplicación al sector noroeste de Madrid (Well correlation by well-logs. Application at NW Madrid basin), Tierra y Tecnología, Colegio Oficial de Geólogos de España ,10, 49-61., ISSN 1131-5016, 10, 49-61, 1995.

565 Forchheimer, P.: Wasserbewegung durch Boden. 45th Edition, Zeitschrift des Vereins deutscher Ingenieure, Düsseldorf, 1901. Green, L. and Duwez, P.: Fluid flow through Porous Metals, J. Appl. Mech., 18, 39-45. https://doi.org/10.1115/1.4010218, 1951

Gueting, N., Vienken, T., Klotzsche, A., van der Kruk, J., Vanderborght, J., Caers, J., ..., Englert, A.: High resolution aquifer characterization using crosshole GPR full-waveform tomography: Comparison with direct-push and tracer test data, Water 570 Resour. Res., 53(1), 49-72, https://doi.org/10.1002/2016WR019498, 2017.

Hasan, A.R., Kabir, C.S.: A study of multiphase flow behavior in vertical wells. SPE Production Engineering, 3(02), 263-272, doi.org/10.2118/15138-PA, 1988. 
Helweg, O. J.: A general solution to the step-drawdown test, Groundwater, 32(3), 363-366, doi:10.1111/j.17456584.1994.tb00652.x., 1994

Hess, A. E.: Identifying hydraulically conductive fractures with a slow-velocity borehole flowmeter, Can. Geotech. J., 23(1), 69-78. https://doi.org/10.1139/t86-008, 1986.

Houben, G. J.: Hydraulics of water wells-flow laws and influence of geometry, Hydrogeol J, 23(8), 1633-1657. https://doi.org/10.1007/s10040-015-1312-8, 2015

Hufschmied, P.: Estimation of three-dimensional statistically anisotropic hydraulic conductivity field by means of a single

well pumping test combined with flowmeter measurements, Hydrogeologie, 2, 163-174, 1986.

Jacob, C. E.: Drawdown test to determine effective radius of artesian well, Transactions of American Society of Civil Engineers, 112 (2312), 1047-1070, 1947.

Kabala, Z. J.: Measuring distributions of hydraulic conductivity and specific storativity by the double flowmeter test, Water Resour. Res., 30(3), 685-690. https://doi.org/10.1029/93WR03104, 1994.

Kabir, C.S., Hasan, A.R.: Simplified wellbore flow modeling in gas-condensate systems. In SPE Annual Technical Conference and Exhibition, OnePetro, doi.org/10.2118/89754-MS, September, 2004.

Karami, G. H., and Younger, P.L.: Analysing step-drawdown tests in heterogeneous aquifers, Q. J. Eng. Geol. Hydrogeol., 35, 295-303, doi:10.1144/1470-9236/2002-9, 2002.

Kawecki, M. W.: Meaningful estimates of step-drawdown tests, Groundwater, 33(1), 23-32, doi:10.1111/j.17456584.1995.tb00259.x., 1995.

Kruseman, G. P. and Ridder, N. A.: Analysis and Evaluation of Pumping Test Data. International Institute for Land Reclamation and Improvement, Holland, ISBN 9070754 207, 1970.

Lane, J. W.: An integrated geophysical and hydraulic investigation to characterize a fractured-rock aquifer, Norwalk, Connecticut (Vol. 1, No. 4133). US Department of the Interior, US Geological Survey, 2002.

595 Li, W., Englert, A., Cirpka, O. A., Vereecken, H.: Three-dimensional geostatistical inversion of flowmeter and pumping test data, Groundwater, 46(2), 193-201, doi: 10.1111/j.1745-6584.2007.00419.x, 2008.

López-Vera, F.: Las Aguas Subterráneas en la Comunidad de Madrid (Groundwater in the Community of Madrid). Consejería de Obras Públicas y Transporte de la Comunidad de Madrid. PIAM, 7, 1985.

López-Vera, F.: La calidad del agua en grandes cuencas sedimentarias. (Water quality in large sedimentary basins.) Red de

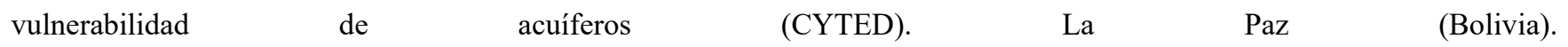
http://tierra.rediris.es/hidrored/apuntes/bolivia/cursolapaz/ferlopve1.html. (last acces 29 January 2021). 2003.

Mathias, S. A. and Todman, L. C.: Step-drawdown tests and the Forchheimer equation, Water Resour. Res., 46, W07514. http://doi.org/10.1029/2009WR008635, 2010.

Molz, F. J., Morin, R. H., Hess, A. E., Melville, J. G. and Guven, O.: The impeller meter for measuring aquifer permeability 605 variations - Evaluations and comparisons with other tests, Water Resour. Res., 25, 1677-1683. https://doi.org/10.1029/WR025i007p01677, 1989. 
Navarro, A., Fernández, A., Doblas, J. G.: Las aguas subterráneas en España (The groundwater in Spain), Instituto Geológico y Minero de España, Book, p. 217-230, 1993.

Nind, T.E.W.: Definition and Measurement of Losses in Hydraulic Head Around a Well Bore, Can. J. Earth Sci., 2(4), 329350, doi.org/10.1139/e65-027, 1965.

Oberlander, P. L. and Russell, C. E.: Process Considerations for Trolling Borehole Flow Logs, Ground Water Monit. Remediat., 26 (3), 60-67. https://doi.org/10.1111/j.1745-6592.2006.00084.x, 2006.

Paillet, F. L.: Flow modeling and permeability estimation using borehole flow logs in heterogeneous fractured formations, Water Resour. Res., 34 (5), 997-1010. https://doi.org/10.1029/98WR00268, 1998.

615 Paillet, F. L.: A field technique for estimating aquifer parameters using flow log data, Groundwater, 38(4), $510-521$. https://doi.org/10.1111/j.1745-6584.2000.tb00243.x, 2000.

Paillet, F. L., Senay, Y., Mukhopadhyay, A., and Szekely, F.: Flowmetering of drainage wells in Kuwait City, Kuwait, J. Hydrol., 234(3-4), 208-227. https://doi.org/10.1016/S0022-1694(00)00261-4, 2000.

Rehfeldt, K. R., Boggs, J. M. and Gelhar, L. W.: Field-study of dispersion in a heterogeneous aquifer: 3. Geostatistical analysis

of hydraulic conductivity, Water Resour. Res., 28(12), 3309-3324. https://doi.org/10.1029/92WR01758, 1992.

Rehfeldt, K. R., Hufschmied, P., Gelhar, L. W. and Schaefer, M. E.: Measuring hydraulic conductivity with the borehole flowmeter, Topical Report EN-6511, Electric Power Research Institute (EPRI), Palo Alto, California, made by Department of Civil Engineering, Massachusetts Institute of Technology, Cambridge, MA, 1989

Riva, M., Ackerer P. and Guadagnini, A.: Interpretation of flowmeter data in heterogeneous layered aquifers, J. Hydrol., 452,

76-82. https://doi.org/10.1016/j.jhydrol.2012.05.040, 2012.

Rorabaugh, M. I.: Graphical and theoretical analysis of step-drawdown test of artesian well, Proceedings of the American Society of Civil Engineers Hydraulics Division, 79, separate No 362, 1-23, 1953.

Ruud, N. C. and Kabala, Z. J.: Numerical evaluation of flowmeter test interpretation methodologies, Water Resour. Res., 32, 845-852. https://doi.org/10.1029/96WR00004, 1996.

630 Ruud, N. C., and Kabala, Z. J.: Numerical evaluation of the flowmeter test in a layered aquifer with a skin zone, J. Hydrol., 203, 101-108. https://doi.org/10.1016/S0022-1694(97)00091-7, 1997.

Ruud, N. C., Kabala, Z. J. and Molz, F. J.: Evaluation of flowmeter-head loss effects in the flowmeter test, J. Hydrol., 224, 55-63. https://doi.org/10.1016/S0022-1694(99)00119-5, 1999.

Samper, J.: La contaminación de las aguas subterráneas (Groundwater contamination), Instituto Geológico y Minero de 635 España, Book, p. 399-408, 1999.

Schneider, C. L. and Attinger, S.: Beyond Thiem: A new method for interpreting large scale pumping tests in heterogeneous aquifers. Water Resour. Res., 44(4), doi:10.1029/2007WR005898, 2008. https://doi.org/10.1029/2007WR005898, 2008.

Shapiro, A. M., Oki, D. S. and Greene, E. A.: Estimating formation properties from early-time recovery in wells subject to turbulent head losses, J. Hydrol., 208, 223-236, doi:10.1016/S0022-1694(98)00170-X, 1998. 
640 Takhanov, D.: Forchheimer model for non-darcy flow in porous media and fractures. MS thesis, Imperial College London, South Kensington, London, 2011

Thiem, G. (1906). Hydrologische Methoden: Dissertation zur Erlangung der Würde eines Doktor-Ingenieurs durch die Königliche Technische Hochschule zu Stuttgart (Doctoral dissertation, JM Gebhardt's verlag), 1906.

Todd, D. K.: Groundwater Hydrology, John Wiley \& Sons, New York, 2nd edition, ISBN : 0471059374, 1980.

645 Van Lopik, J. H., Snoeijers, R., van Dooren, T. C., Raoof, A., and Schotting, R. J.: The effect of grain size distribution on nonlinear flow behavior in sandy porous media, Transp. Porous Media, 120(1), 37-66, https://doi.org/10.1007/s11242-0170903-3, 2017.

Van Tonder, G. J., Botha, J. F. and. Van Bosch, J.: A generalized solution for step-drawdown tests including flow dimension and elasticity, Water S. A., 27(3), 345-354, https://doi.org/10.4314/wsa.v27i3.4978, 2001.

650 Villanueva, M. and Iglesias, A.: Pozos y Acuíferos (Wells and Aquifers). Ibergesa, Madrid (ISBN 84-7474-258-7), 426 p, 1984.

Weisbach, J.: Lehrbuch der Ingenieur- und Maschinen-Mechanik Vol. 1: Theoretische Mechanik (Textbook of Engineering and Machinery Mechanics, Vol. 1: Theoretical Mechanics), Vieweg und Sohn, Braunschweig. 535 p., 1845.

Wu, B., Firouzi, M., Mitchell, T., Rufford, T.E., Leonardi, C., Towler, B.: A critical review of flow maps for gas-liquid flows

655 in vertical pipes and annuli, Chem. Eng. J., 326, 350-377, doi.org/10.1016/j.cej.2017.05.135, 2017.

Xiang, J.: The evaluation of the flowmeter test in three-layer aquifers and the influence of disturbed zones, J. Hydrol., 166(1-

2), 127-145. https://doi.org/10.1016/0022-1694(94)02570-2, 1995.

Yeh, T.C.J., Jin, M., Hanna, S.: An iterative stochastic inverse method: conditional effective transmissivity and hydraulic head fields, Water Resour. Res. 32 (1), 85-92, doi.org/10.1029/95WR02869, 1996.

660 Yélamos, J.G., Villarroya, F.: El acuífero terciario detrítico de Madrid: pasado, posibilidades actuales y retos pendientes (The Tertiary Detritical Aquifer of Madrid: past times, present possibilities and pending. challenges), Enseñanza de las Ciencias de la Tierra, 15-3, 317-324. (I.S.S.N.: 1132-9157), 2007.

Zech, A., Dietrich, P., Attinger, S., Teutsch, G.: A field evidence model: how to predict transport in heterogeneous aquifers, Hydrol. Earth Syst. Sci., 25, 1-15, doi.org/10.5194/hess-25-1-2021, 2021.

665 Zha, Y., Yeh, T-C. J., Shi, L., Huang, S-Y., Wang, W. Wen, J-C.: Quasi-steady state conditions in heterogeneous aquifers during pumping tests. Adv. Water Resour., 106 95-110. http://dx.doi.org/10.1016/j.advwatres.2017.03.017, 2017.

Zlotnik, V.A. and Zurbuchen, B. R.: Field study of hydraulic conductivity in a heterogeneous aquifer: Comparison of singleborehole measurements using different instruments, Water Resour. Res., 39 (4), 1101-1112. https://doi.org/10.1029/2002WR001415, 2003a.

670 Zlotnik, V. A. and Zurbuchen, B. R.: Estimation of hydraulic conductivity from borehole flowmeter tests considering head losses. J. Hydrol., 281(1-2), 115-128, https://doi.org/10.1016/S0022-1694(03)00204-X, 2003b. 